\title{
The Impact of the Internet on Social \& Psychological Well-Being of School Going Children
}

\author{
Deepak Sharma $^{1}$, Prof. D D Aggarwal ${ }^{2}$, Anju Joshi Sharma ${ }^{3}$
}

\section{ABSTRACT}

This study investigated the children's Internet use behaviour and how the Internet usage changes children's daily lives. 50 children in 9th to12th Class participated in survey. Particularly, this study examined how children allocated their time to different media and daily activities and the relationship between children's Internet use and level of physical activities, social involvement and relationship, and loneliness. This study found no displacement effect of the Internet on children's daily activities. Rather, it was found that children who spend more time on the Internet were more likely to spend more time with other media, more time on some kind of physical activities, and were more socially involved. The Internet provided a place for communication and social relationships for children. Net-generation children surrounded by media were not necessarily giving up other activities that were also important for their intellectual, physical, social and psychological development.

Keywords: Internet, Social, Psychological Well-Being, School Children.

It is often assumed that internet use is maintained by the positive reinforcing consequences of such use; for example, its production of entertainment, use as a pass-time, or in informationseeking. Moreover, it has been suggested that high use may be motivated by factors such as identify-clarification, certainly in adolescent users. However, it is often noted that other psychological factors, not linked to positive reinforcing consequences, are often implicated in maintaining high levels of problematic behaviours. Also, the credibility of the Internet as a medium is questionable. Given that information on the Internet is unchecked and that anyone can be an author on the Internet, the Internet might provide inaccurate, biased, and misleading information (Flanagin, \&Metzger, 2000). However, lots of people seem to believe what the Internet offers to them.

\footnotetext{
${ }^{1}$ Ph.D. Scholar, Psychology, Department of Arts, Mahatma Gandhi University, Meghalaya, India

${ }^{2}$ Prof. Retd. Faculty of Arts, University of Delhi, India

${ }^{3}$ Ph.D. Scholar, Biotechnology, Mewar University, India

*Responding Author

(c) 2016 I D Sharma, D Aggarwal, A Joshi; licensee IJIP. This is an Open Access Research distributed under the terms of the Creative Commons Attribution License (http://creativecommons.org/licenses/by/2.0), which permits unrestricted use, distribution, and reproduction in any Medium, provided the original work is properly cited.
} 


\section{Internet and Children}

"Children are not viewers; they are users and they are active. They do not just observe; they participate. They inquire, discuss, argue, play, shop, critique, investigate, ridicule, fantasize, seek, and inform.” By Tapscott (1998b).

Almost all new media, including radio, television, computer and the Internet, have been considered a potential positive and negative influence on children. Children have been treated as the most vulnerable agents of media influence. Moreover, the concern about media effects on children has grown as media occupy a large portion of children's free time and become available in almost every home or school. Content on the Internet is one of the potential problems for children. Children are able to get any information through the Internet without adults' mediation in various settings including home, school, and library. Content pertaining to violent information, such as how to make a bomb, pornographic materials, hate information are among those that can influence children negatively. Exposure to the object of the problematic behaviours has been found to reduce mood, especially in individuals addicted to pornography. As both of these reasons (i.e. gambling and pornography) for use of the internet are strongly associated with problematic internet use it may well be that these factors may also contribute to internet addiction .Indeed, it has been suggested that such negative impacts of engagement in problematic behaviour may, in themselves, generate further engagement in these high probability problematic behaviours in an attempt to escape these negative feelings.

Children as Internet users could be the easiest victims of misinformation on the Internet since children are still in a developmental stage in terms of reasoning and judgment. Also the fact that information seeking is one of the most common Internet activities provides a question about how people perceive the credibility of the information on the Internet. As children depend on the Internet more than before, they seem to trust all the information from the Internet. Thus, whether a high level of Internet usage is related to the level of credibility of the Internet is an interesting question to investigate

In general, there is no difference between genders in terms of Internet involvement (Demner, 2001). Girls use the Internet as much as boys. However, girls and boys used the Internet in different ways. Girls reported that they used the Internet for education, schoolwork, e-mail and chat rooms whereas boys were likely to use the Internet for entertainment and games. Thus, when it comes to the Internet, the stereotype of girls' having technology phobia might disappear.

\section{MATERIALS AND METHODS}

For the main data collection, this study used self-reported survey from children $9^{\text {th }}$ to $12^{\text {th }}$ Class during February 2016. In detail, this sample consists of two private schools and three Government schools. The survey package included one cover letter, two parental consent forms, two child assent forms, and the questionnaire. Children took the questionnaire home and parents 
or guardian reviewed the questionnaire and signed the consent forms. Children were asked to fill out 30 questions.

\section{DATA ANALYSIS}

Table.1 Gender Wise Distribution of Respondents

\begin{tabular}{|l|l|l|}
\hline Sex & Number & Percentage \\
\hline Male & 30 & 60 \\
\hline Female & 20 & 40 \\
\hline Total & $\mathbf{5 0}$ & $\mathbf{1 0 0}$ \\
\hline
\end{tabular}

Table-2Demographic Data

\begin{tabular}{|l|l|}
\hline Age & Number of Respondents \\
\hline 14 Years Old & $07(14 \%)$ \\
\hline 15 & $10(20 \%)$ \\
\hline 16 & $15(30 \%)$ \\
\hline 18 & $12(24 \%)$ \\
\hline Whom they live with & $06(12 \%)$ \\
\hline Both parents & \\
\hline Mother & $42(84 \%)$ \\
\hline Father & $02(4 \%)$ \\
\hline Grand Parents & $00(0 \%)$ \\
\hline School System & $06(12 \%)$ \\
\hline Private & \\
\hline Government & $35(70 \%)$ \\
\hline
\end{tabular}

Table.3 Face-to-Face Interaction with Family per Day

\begin{tabular}{|l|l|l|l|l|l|l|}
\hline Interaction & $\begin{array}{l}\text { Not at } \\
\text { all }\end{array}$ & Rarely & Sometimes & Often & Very often & Total \\
\hline With parents & 06 & Nil & Nil & 12 & 32 & 50 \\
\hline With siblings & Nil & Nil & 15 & 05 & 30 & 50 \\
\hline
\end{tabular}


Table.4 Types of Internet Use

\begin{tabular}{|l|l|}
\hline Internet Use For & Number of Respondents \\
\hline Surfing the web & 28 \\
\hline Research for school works & 34 \\
\hline Playing games & 42 \\
\hline E-mail & 12 \\
\hline Instant messaging(Chatting) & 48 \\
\hline Downloading music files & 26 \\
\hline Information about entertainment & 19 \\
\hline Information about sports & 20 \\
\hline Information about hobbies & 09 \\
\hline Shopping & 16 \\
\hline Checking news & 23 \\
\hline Adult Websites/Content & 10 \\
\hline Social Websites & 45 \\
\hline
\end{tabular}

Table-5Amount of Time Spent on Internet Activities per Day

\begin{tabular}{|l|l|l|l|l|}
\hline Time interval & 1-2 Hours & 2-4 Hours & 4-6 hours & More than 6 hours \\
\hline No. of Respondents & 02 & 33 & 05 & 10 \\
\hline
\end{tabular}

Table-6 Perception of the Internet Credibility

\begin{tabular}{|l|l|}
\hline Items & No. of Respondents \\
\hline Believability & 48 \\
\hline Accuracy & 40 \\
\hline Trustworthiness & 32 \\
\hline Completeness & 44 \\
\hline
\end{tabular}

\section{RESULTS}

\section{Sample Description}

Respondents consisted of 30 boys (60\%) and 20 girls (40\%). About $70 \%$ of respondents attend public school and 30\% from Government School. The range of age among respondents was 14 through 18 years old (Mean age= 16 Years). The majority of respondents were aged from 15 through 17. About $84 \%$ of children reported that they lived with both parents while $12 \%$ of children said they lived with others (e.g. Grandparents). $4 \%$ of children lived with mother while none of the of children lived with father.

\section{Survey analysis}

It was interested in the general characteristics of children's media use, such as watching television, reading newspaper, listening to radio, playing video games, reading books and using the Internet. Over $60 \%$ of children did not read a newspaper at all. Over half of children watched television about 2 hours per day. 
Research Questionnaire addressed the general characteristics of children's Internet use, and general perception about the credibility of the Internet and the effect of the Internet on their time use. About $65 \%$ of children said they did not use the Internet at school at all. The major online activity by children was Instant messaging(Chatting) followed by playing games, Social website, research for schoolwork, followed by checking News, e-mail, downloading music files, information about entertainment, information about sports, information about hobbies, shopping. Children generally perceived that the Internet had some negative impact on other young kids but not themselves.

Findings show that girls spent more time on the Internet for email, instant messaging, chatting room, and shopping than boys. Boys used the Internet more for playing games, information about sports, and information about hobbies than girls. Study suggests that children who use the Internet for communication are more likely to participate in social events than children who use the Internet for information or entertainment. The amount of Internet use was negatively associated with face-to-face interaction with siblings. The more Internet use, the less face-to-face interaction with siblings. Study reveals that children who use the Internet for information are more likely to place more importance on helping others while children who use the Internet for entertainment are more likely to place less importance on helping others. The findings show that children who spend less time with the Internet felt lonelier than children who use the Internet a lot.

\section{DISCUSSION}

The purpose of this study was to examine children's Internet use and how Internet usage influences children's daily lives. This study sought to determine if there was a possible effect for daily activities and an impact on children's social and psychological well-being. Results revealed that children's amount of Internet use was predicted by the number of Internet-capable computers at home, Mobile Phones, ownership of a computer with Internet access by child, and Internet experience. Children who spent more time on the Internet also spent more time with other existing media, including television, radio, video games, and books. The amount of Internet use was found to decrease face-to-face interaction with siblings. With respect to the types of Internet use, children used the Internet for communication with friends. The Internet was a place where children continued to maintain friendship from offline to online. These data supported the Internet as a place for social relations and communication.

Although this study found that high Internet use children felt less socially lonely than those with low users, the high Internet use children may have higher emotional loneliness. Thus, it is recommended that further study concerning loneliness and Internet use should examine both social and emotional loneliness. It was found that children who were high Internet users spent more time on social events. However, it should be noted that social involvement was positively associated only with children's Internet use for communication but not with Internet use for 
information and entertainment. Once again, the types of Internet use and not the total amount of Internet use explained the involvement with other activities.

This study of course has several limitations. First, although it tried to include every possible activity, such as sleeping, eating, house chores, and "hanging out," all activities could not be measured. Second, this study also has methodological shortcomings. This study used the selfreport method for data collection, which has some limitations. Children may not estimate their time spent on each activity as accurately as adults. Third, Similar to other survey research, this study doesn't not provide evidence of cause and effect. Gustavo (2001) found that adolescents who were more socially isolated were more likely to be frequent Internet users, although he found that Internet use did not displace other social activities. Similarly, although this study found that children who use the Internet more felt less lonely, it may be possible that children's loneliness lead them to spend more time on the Internet.

Overall, this study found that the more time children spend on the Internet, the more time they are likely to spend with other media, the more time on some kind of physical activities, and were more socially involved they are likely to be. The Internet provides a place for communication and social relationships for children. Net-generation children surrounded by media are not necessarily giving up other activities that are also important for their intellectual, physical, social and psychological development.

For future study, the following things are recommended. First, this study strongly suggests that types of Internet use should be examined to test the displacement effect of new media. Online activities, particularly online game playing, chat rooms, and bulletin boards are important in investigating displacement of children's social relations and involvements. In fact, chat rooms and bulletin boards are mainly for communication and relationships with people. People talk to each other and are making friends. Sometimes online relationships lead to off line relationships. Nobody can tell if online relationships are inferior to off line relationships. Some people have more serious and intimate relationships on line where they can get understanding and support. Online game playing is a context for communication as well as playing games. Many online games provide chatting room for people who have the same interest-the online game. Thus, examining the impact of the specific types of Internet use on children's daily activities will provide better understanding of the influence of the Internet on children.

\section{REFERENCES}

Ahser, S.R., Hymel, S., \&Renshaw, P.D. (1984).Loneliness in children. Child Development, 55, 1456-1464.

Bianchi, S.M., \& Robinson, J. (1997). What did you do today? Children's use of time, family composition, and acquisition of social capital. Journal of Marriage \& family, 59, 332344. 
Calfas, C.J., \& Taylor, W.C. (1994).Effects of physical activity on psychological variables of children.Pediatric Exercise Science, 6, 406-423.

Cassidy, J. \& Asher, S.R. (1992).Loneliness and peer relationships in young children. Child Development, 63, 350-365.

DiMaggio, P., Hargittain, E., Neuman, W.R., \& Robinson, J.P. (2001).Social implications of the Internet. Annu. Rev. Sociol. 27, 307-336.

Flanagin, A., J., \& Metzger, M.J. (2000).Perceptions of Internet information credibility. Journalism and Mass Communication Quarterly, 77, 515-540.

Gustavo, S.M. (2001). Social relationships and Internet use among adolescents in Israel. Social Science Quarterly, 82, 329-339.

Hampton, K.N., \& Wellman, B. (1999).Netville online and offline. American Behavioral Scientist, 43, 475-491

Nie, N.H., Erbring, L. (2000).Stanford Institute for the Quantitative Study of Society. (2000, February 17). Internet and society: A preliminary report. Retrieved December 27, 2002, from http://www.stanford.edu/group/siqss/Press_Release/internetStudy.html

Page, R.M., Frey, J., Talbert, R., \& Falk, C. (1992). Children’s feelings of loneliness and social dissatisfaction: Relationship to measures of physical fitness and activity. Journal of Teaching in Physical Education, 11, 211-219.

Parks, M. \& Roberts, L. (1998). 'Making MOOsic’: The development of personal relationships on line and a comparison to their off-line counterparts. Journal of Social and Personal relationships, 15, 517-537.

Tapscott, D. (1998b). The net generation and the school. Milken Family Foundation. Retrieved January 4, 2003, from http://www.mff.org/edtech/article.taf

Weiss, R. (1973). Loneliness: The experience of emotional and social isolation. Cambridge: The MIT Press.

How to cite this article: D Sharma, D Aggarwal, A Joshi (2016), The Impact of the Internet on Social \& Psychological Well-Being of School Going Children, International Journal of Indian Psychology, Volume 3, Issue 3, No. 6, DIP: 18.01.105/20160303 